\title{
An Inventory Control Policy with Tracking Information for Dual-channel Supply Chains
}

\author{
Hidehiro Nagao \\ Katsuhiko Takahashi \\ Katsumi Morikawa \\ Daisuke Hirotani \\ Hiroshima University, Higashi-Hiroshima, Japan
}

\begin{abstract}
Recently, many products have been sold through retail stores and direct sales via the Internet. For dual-channel supply chains, Chiang and Monahan (2010) and Chiang (2010) have proposed an inventory control policy; however, they assumed one-for-one replenishment and short replenishment lead times. For single-channel supply chains with long and uncertain replenishment lead times, Liu et al. (2009) have introduced tracking information into inventory control. However, they did not consider the cost of tracking information. Therefore, in this paper, a Markov chain model for dual-channel supply chains with long and uncertain replenishment lead times is developed, and an inventory control policy is proposed that considers tracking information and its cost. The performance of the proposed policy is evaluated and compared with two policies, one without tracking information and the other without reduplicated normal replenishment. The results show the effectiveness of the proposed policy.
\end{abstract}

Keywords: Dual-channel supply chain, Replenishment lead time, Lot replenishment, Tracking information, Markov analysis.

\section{Introduction}

Real supply chains in industries have become more and more complicated, and more and more papers on supply chains have been published. For example, Liu et al. (2009) have considered the tracking information for real-time shipping in supply chains, Chen et al. (2001) have considered the coordination of a supplier and retailers in a supply chain with a supplier and multiple retailers. Zhou et al. (2008) have considered a coordination under an inventory-level-dependent demand rate, and Yao (2009) have considered a batch ordering policy for assemble-to-order system. However, all of the papers have considered inventory management models for single-channel supply chains.

Recently, many manufacturers have sold their products through retail stores and in direct sales via the Internet. Therefore, the study of dual-channel supply chains has increased. For the dual-channel supply chain, the coordination between the channels should be considered for managing the supply chain totally. In considering the coordination beteen channels, the coordination of prices between the channels is an important topic, and Kurata et al. (2007), Cai et al. (2009), Huang and Swaminathan 
(2009), and Hua et al. (2010) have considered the topic. Also, Liu et al. (2010) have considered the joint decision on production and pricing. Also, Mohsen and Kourosh (2009) have considered the order dependent lead times and prices, and Cao and Yushin (2009) have considered a channel coordination through a revenue sharing contract.

The next important topic of dual-channel supply chains is the coordination of inventories, and Bendoly (2004) and Mahara et al. (2009) have considered the inventory pooling. Chiang and Monahan (2005) and Chiang (2010) have developed inventory control policies, Tamer (2005) have considered competition and coordination, and Dumrongsiri et al. (2008) have considered the difference from single channel supply chain.

In this paper, the inventory control problem in dual-channel supply chains will be considered. Even if the price and configuration of supply chain have been determined, the performance of supply chain can be improved by coordinating the inventories in the dual channels. Otherwise if the coordination would be failed, the mismatch of demand and supply between the dual channels decreases the performance of supply chain.

This paper will deal with an inventory control problem in dual-channel supply chains based on the papers of Chiang and Monahan (2005) and Chiang (2010). They have suggested a new inventory control policy that uses Markov analysis. In real environments, replenishment involves a lot replenishment system or a batch ordering policy like Yao (2009), but the replenishment in their model was a one-for-one system. They did not consider demand arrivals during replenishments with long and uncertain lead times from the warehouse to the retail store. Therefore, it is necessary to consider reduplicating replenishment and emergency replenishment to deal with demands that occur during long and uncertain replenishment lead times in a Markov chain model of dual-channel supply chains. When a replenishment lead time is long but constant, replenishments should overlap. However, when a replenishment lead time is long and uncertain, it is necessary to determine the progress of the replenishment to deal with demand. Also, even if the overlapped or reduplicated replenishment has been considered, an additional replenishment with short lead time, that is, an emergency replenishment is necessary to avoid or reduce lost sales.

For the purpose, this paper will utilize the idea of Liu et al. (2009) and determine the progress of the replenishment to deal with demand. Liu et al. (2009) have researched information such as the current position and weight of a shipment, which is called tracking information. For single-channel supply chains, they showed that they could determine the optimal ordering time and order quantity by using tracking information, even if the replenishment lead time from the warehouse to the retail store was long and uncertain. However, they considered only normal replenishment, even if the lead time was long and uncertain; they did not consider emergency replenishment. The problems caused by uncertainty in replenishment lead times cannot be solved with normal replenishment only. In addition, they did not consider the cost of using tracking information.

Therefore, a Markov chain model that considers demand arrivals during long and uncertain replenishment lead times for dual-channel supply chains and an inventory control policy that uses tracking information are proposed in this paper. 
In the control policy, reduplicated replenishment and emergency replenishment are introduced, and the cost of using tracking information is considered. The performance of the proposed policy is evaluated and compared with two policies, one without tracking information and the other without reduplicated normal replenishment. The results show the effectiveness of the proposed policy.

\section{Dual-channel Supply Chain Model}

In this section, a model of dual-channel supply chain will be developed, and inventory control policy for the model will be formulated. After summering notations in this paper, a model from previous literature will be introduced, and the proposed model will be developed.

\section{Notations}

In this paper, the following parameters, state variables and decision variables are used as notations.

(Parameters)

$\alpha$ : the rate at which customers select the direct channel is determined by the direct-channel preference rate. $\left(\lambda_{d}=\alpha \lambda\right)$.

$\lambda_{\mathrm{d}}$ : the rate of demand arrival of customers arrive at the direct channel $\left(\lambda_{\mathrm{r}}=(1-\alpha) \lambda\right)$.

$\lambda_{\mathrm{r}}$ : the rate of demand arrival of customers arrive at the retail channel

$\mu_{\mathrm{w}}$ : the rate of production from the factory to the warehouse.

$\mu_{\mathrm{r}}$ : the rate of replenishment from the warehouse to the retail store in the model of Chiang and Monahan, and the rate of emergency replenishment from the warehouse to the retail store in the proposed model. the retail store.

$\mathrm{K}$ : the number of stages of a normal replenishment from the warehouse to

S: the lot size of a normal replenishment.

$\mu_{\mathrm{R} 1}$ : the rate of starting a normal replenishment from the warehouse.

$\mu_{\mathrm{R} 1}$ : the rate of moving, products in stages to the last stage $\mathrm{K}$ one by one. retail store.

$\mu_{\mathrm{Rl}}$,: the rate of completing a normal replenishment from stage $\mathrm{K}$ to the

$\mathrm{L}_{\mathrm{R}}$ : the average lead time of a normal replenishment.

$\mathrm{L}_{\mathrm{r}}$ : the average lead time of emergency replenishment.

$h_{w}$ : the unit inventory holding cost at the warehouse.

$h_{r}$ : the unit inventory holding cost at the retail store.

1: the unit shortage cost. 

information.

es: the unit emergency replenishment cost.

ti: the unit tracking information cost.

(State variables)

$\mathrm{z}_{1}$ and $\mathrm{z}_{2}$ : the current stage of a normal replenishment collected as tracking

$\mathrm{x}$ : the current inventory on hand at the warehouse.

$\mathrm{y}$ : the current inventory at the retailer.

$\pi_{\mathrm{xyz} 1 \mathrm{z2}}$ : the steady-state probability of state $\left(\mathrm{x}, \mathrm{y}, \mathrm{z}_{1}, \mathrm{z}_{2}\right)$.

$\phi_{\mathrm{xyz}_{1} z_{2}}$ and $\tau_{\mathrm{xyz}_{1} z_{2}}^{\mathrm{r}}$ : the $0-1$ variables that show the conditions before and after the transition in Equation 1, respectively.

$\kappa_{\mathrm{xyz}_{1} z_{2}}$ and $\theta_{\mathrm{xyz}_{\mathrm{z}, \mathrm{z}}}$ : the $0-1$ variables that show the conditions before and after the transition in Equation 2, respectively.

$\eta_{\mathrm{xyz}_{1} \mathrm{z}_{2}}$ and $\rho_{\mathrm{xyz}_{1} \mathrm{z}_{2}}$ : the 0 -1 variables that show the conditions before and after the transition in Equation 3, respectively.

$\epsilon_{\mathrm{xyz}_{1} z_{2}}$ and $\tau_{\mathrm{xyz}_{1} \mathrm{z}_{2}}^{\mathrm{w}}$ : the $0-1$ variables that show the conditions before and after the transition in Equation 4, respectively.

$\epsilon_{\mathrm{xyz}_{1} \mathrm{z}_{2}}^{\prime}$ and $\tau_{\mathrm{xyz}_{1} \mathrm{z}_{2}}^{\mathrm{w}^{\prime}}$ : the 0-1 variables that show the conditions before and after the transition in Equation 5 , respectively.

$\epsilon^{\prime \prime}{ }_{\mathrm{xyz}_{1} \mathrm{z}_{2}}$ and $\tau_{\mathrm{xyz}_{1} \mathrm{z}_{2}}^{\mathrm{w}^{\prime \prime}}$ : the $0-1$ variables that show the conditions before and after the transition in Equation 6, respectively.

$\chi_{\mathrm{x}}$ and $\tau_{\mathrm{x}}$ : the $0-1$ variables that show the condition where the transition of demand arrival at direct channel can reduce from and to the current inventory on hand at the warehouse, respectively.

$\delta_{\mathrm{y}}$ and $\tau_{\mathrm{y}}$ : the $0-1$ variables that show the condition where the transition of demand arrival at retail store can reduce from and to the current inventory on hand at the retail store, respectively.

$\varphi_{z_{1} z_{2}}$ and $\tau_{z_{1} z_{2}}$ : the $0-1$ variables that show the condition where the stage of normal replenishment can transit from and to the current stage, respectively.

$\gamma_{z_{1} z_{2}}$ and $\tau_{z_{1} z_{2}}^{\prime}$ : the $0-1$ variables that show the condition where the normal replenishment can finish from and to the current stage, respectively.

$v_{z_{1} z_{2}}$ and $\sigma_{z_{1} z_{2}}$ : the 0-1 variables that show the condition where the stage of normal replenishment can transit from and to the current stage, respectively when a reduplicated normal replenishment has already been begun.

$\mathrm{O}_{\mathrm{z}_{1} \mathrm{z}_{2}}$ and $\zeta_{\mathrm{z}_{1} \mathrm{z}_{2}}$ the $0-1$ variables that show the condition where the stage of reduplicated normal replenishment can transit from and to the current stage, respectively.

$\omega_{z_{1} z_{2}}$ and $\psi_{z_{1} 1_{2}}$ : the 0-1 variables that show the condition where the reduplicated normal replenishment can finish from and to the current stage, respectively.

TC: the total cost. 
$\mathrm{C}_{\mathrm{H}}$ : the inventory holding cost.

$\mathrm{C}_{\mathrm{L}}$ : the shortage cost.

$\mathrm{C}_{\mathrm{ER}}$ : the emergency replenishment cost.

$\mathrm{C}_{\mathrm{TI}}$ : the tracking information cost.

(Decision variables)

$\mathrm{X}$ : the maximum inventory level of the warehouse.

Y: the maximum inventory level of the retailer.

S: the lot size of normal replenishment.

$\mathrm{a}, \mathrm{b}$, and c: coefficients that determine the states of starting a reduplicated normal replenishment. replenishment.

$\mathrm{d}, \mathrm{e}$, and f: coefficients that determine the states of starting an emergency

\section{A Model from Previous Literature}

Figure 1 shows the dual-channel supply chain model with direct sales from a warehouse and sales by a retail store developed by Chiang and Monahan (2005). The assumptions are given below.

- The dual-channel supply chain model consists of direct sales from the warehouse and sales by the retail store, and the prices are the same.

- The rate at which customers select the direct channel is determined by the directchannel preference rate $\alpha$.

- The demands of customers arrive at the direct and retail channels according to Poisson distributions at arrival rates $\lambda_{\mathrm{d}}$ and $\lambda_{\mathrm{r}}\left(\lambda_{\mathrm{d}}=\alpha \lambda, \lambda_{\mathrm{r}}=(1-\alpha) \lambda\right)$, respectively.

- Demands arrive when low stocks are lost as sales losses.

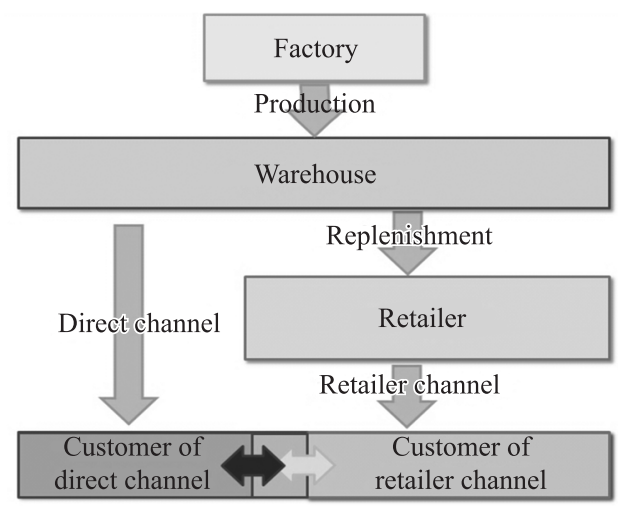

Figure 1. Dual-channel supply chain model. 
- Production is done according to a Poisson distribution at production rate $\mu_{\mathrm{w}}$ one for one from the factory to the warehouse. The production time follows the exponential distribution of the average $1 / \mu_{\mathrm{w}}$.

- Replenishment is done according to a Poisson distribution at replenishment rate $\mu_{\mathrm{r}}$ one for one from the warehouse to the retail store. The replenishment time follows the exponential distribution of the average $1 / \mu_{\mathrm{r}}$.

For the model shown in Figure 1, Chiang and Monahan (2005) proposed an inventory control policy with limits on production and replenishment. However, their Markov model did not express state transition during a replenishment lead time from start to completion, as shown in Figure 2. Therefore, when the replenishment lead time in the model was long and uncertain, a change in inventory quantity could not be expressed correctly.

Liu et al. (2009) researched information such as the current position and weight of a shipment, which is called tracking information. For single-channel supply chains, they showed that they could determine the optimal ordering time and order quantity by using tracking information, even if the replenishment lead time from the warehouse to the retail store was long and uncertain, as shown in Figure 3.

However, they did not consider emergency replenishment; therefore, they could not deal with uncertainty in the replenishment lead time. In addition, they did not consider the cost of using tracking information.

\section{Proposed Model}

In this paper, based on Chiang and Monahan (2005) and Liu et al. (2009), a dual-channel supply chain model with long and uncertain lead times of lot replenishment and tracking information is developed. A dual-channel supply chain model consisting of direct sales from a warehouse and sales by a retailer is considered. The warehouse

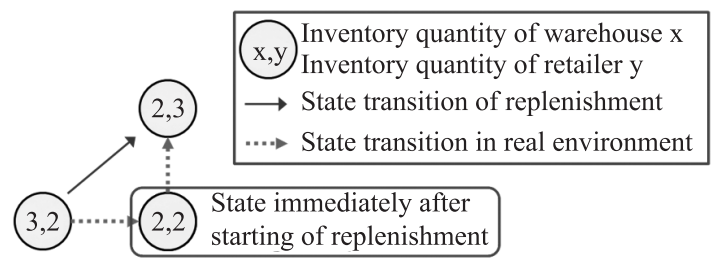

Figure 2. Markov chain of Chiang and Monahan (2005).

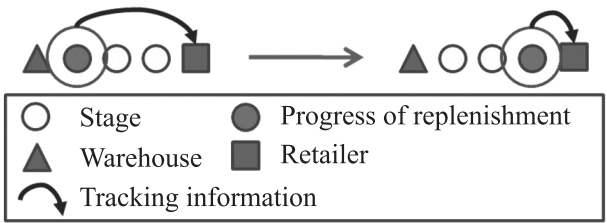

Figure 3. Tracking information in Liu et al. (2009). 
can fulfill direct-channel demand with warehouse inventory. Warehouse inventory is produced in a factory by one-for-one production. Similarly, the retailer can fulfill retailer-channel demand with retailer inventory. The warehouse can fulfill each order from the retailer and transport a product immediately after receiving an order. However, in many cases, the replenishment process between the warehouse and the retailer is not instantaneous but uncertain. Therefore, in this model, products transported from the warehouse pass through several stages before they arrive at the retailer, and each stage represents the current position of a transported product. Thus, the stages represent the states of progress of replenishment. To obtain tracking information is to determine the state of progress of replenishment. This dual-channel supply chain model gives the state of progress of replenishment as well as the states of the warehouse and retailer inventories. Replenishment is determined with this information. For a realistic and flexible supply chain, two kinds of replenishment are introduced. The first is normal replenishment, which has a long and uncertain lead time. The lot size for normal replenishment is greater than 1 . Products in normal replenishment pass through several stages before they arrive at the retailer. To avoid an increase in inventory caused by a long lead time, a normal replenishment can be reduplicated only once at a time. The time to release the reduplicated normal replenishment is determined from information about the progress of the normal replenishment.

The second replenishment introduced in this paper is emergency replenishment, which uses airplane or bullet train and has a shorter lead time than normal replenishment. Emergency replenishment is done by the one-for-one method and does not have stages. Therefore, when a normal replenishment has already been ordered, emergency replenishment enables a dual-channel supply chain to fulfill demands that occur during the lead time of the normal replenishment. However, an emergency replenishment has a substantial ordering cost compared with a normal replenishment. Moreover, another cost is incurred in using tracking information. Therefore, it is necessary to find the optimal replenishment that combines the two kinds of replenishment by using tracking information.

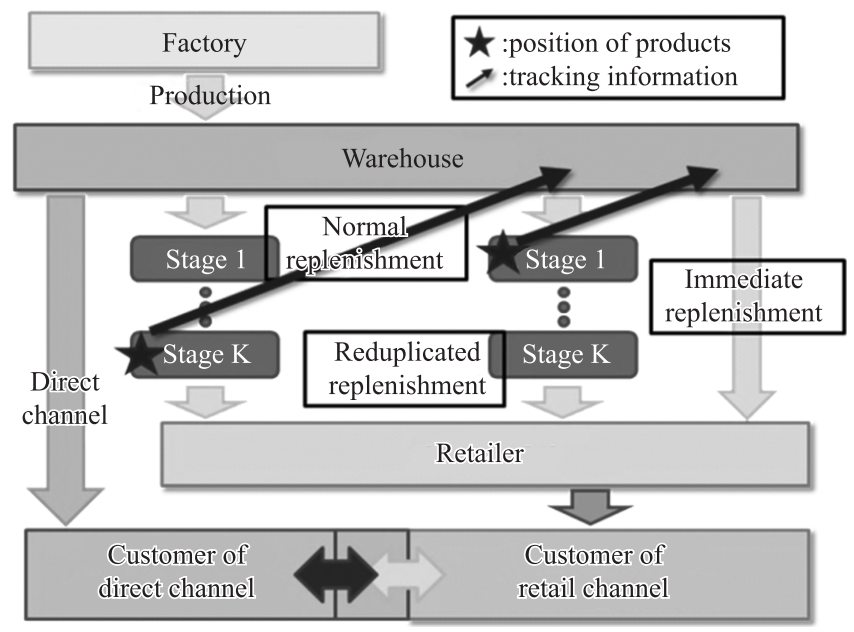

Figure 4. Proposed model. 
The assumptions of replenishment in this paper are given below.

- A normal replenishment from the warehouse to the retail store has $\mathrm{K}$ stages. The lot size of a normal replenishment is $\mathrm{S}$, which is greater than 1 .

- At state transition rate $\mu_{\mathrm{R} 1}$, a normal replenishment starts from the warehouse to stage 1. At state transition rate $\mu_{\mathrm{R} 1}$, products are moved in stages to the last stage $\mathrm{K}$ one by one. At state transition rate $\mu_{\mathrm{R} 1}$,", a normal replenishment is completed from stage $\mathrm{K}$ to the retail store.

- When a normal replenishment has been released, only one more normal replenishment can be released as a reduplicated normal replenishment. The cross over between the former normal replenishment and the latter reduplicated normal replenishment is allowed.

- Transitions at rates $\mu_{\mathrm{R} 1}, \mu_{\mathrm{R} 1}$, and $\mu_{\mathrm{R} 1}$, follow Poisson distributions. Therefore, the average lead time $L_{R}$ of a normal replenishment is the sum of the reciprocals of these rates.

- After the reduplicated normal replenishment has been released, emergency replenishments will be released by the one-for-one method from the warehouse to the retail store. The lead time of emergency replenishment, $\mathrm{L}_{\mathrm{r}}$, follows the exponential distribution of the average $1 / \mu_{\mathrm{r}}$, and it is sufficiently shorter than the lead time of normal replenishment, $L_{R}$. Then, the stage during emergency replenishment is not considered, and the cost for emergency replenishment is higher than the normal replenishment.

- For using tracking information, tracking information cost that is proportional with the number of tracking stages is incurred.

\section{Proposed Inventory Control Policy}

By obtaining the status information of a normal replenishment $z_{1}$ and $z_{2}$ as tracking information, the inventory control policy determines $\mathrm{X}$ (the maximum inventory level of the warehouse), Y (the maximum inventory level of the retailer), $\mathrm{S}$ (the lot size of normal replenishment), a, b, c (coefficients that determine the states of starting a reduplicated normal replenishment), $d, e, f$ (coefficients that determine the states of starting an emergency replenishment). been satisfied.

At first, a normal replenishment is begun if the following conditions have

- If the stage of the normal replenishment $z_{1}$ is zero and the stage of the reduplicated normal replenishment $\mathrm{z}_{2}$ is zero.

$\mathrm{S} \leq \mathrm{x} \leq \mathrm{X}$ and $0 \leq \mathrm{y} \leq \mathrm{Y}-\mathrm{S}$

When a normal replenishment has already been begun, a reduplicated normal replenishment is begun if the following conditions have been satisfied.

- If the stage of the normal replenishment $z_{1}$ is not zero and the stage of the reduplicated normal replenishment $\mathrm{z}_{2}$ is zero. 
$S \leq x \leq X$ and $0 \leq y \leq Y-2 S$ and $\left\{\begin{array}{l}z_{1} \leq a x+b y+c(a \geq 0 \text { and } b<0) \\ z_{1} \geq a x+b y+c(a \leq 0 \text { and } b>0)\end{array}\right.$

When a reduplicated normal replenishment has already been begun, emergency replenishments are begun if the following conditions have been satisfied.

- If the stage of the normal replenishment $z_{1}$ is not zero and the stage of the reduplicated normal replenishment $\mathrm{z}_{2}$ is not zero.

$1 \leq \mathrm{x} \leq \mathrm{X}$ and $0 \leq \mathrm{y} \leq \mathrm{Y}-2 \mathrm{~S}-1$ and $\mathrm{z}_{1}+\mathrm{z}_{2} \leq \mathrm{dx}+\mathrm{ey}+\mathrm{f}(\mathrm{d} \geq 0$ and $\mathrm{e}<0)$

In the above control policy, by using tracking information, the normal and emergency replenishments can be decided according to the stages of normal replenishment $z_{1}$ and $z_{2}$ in order to reduce the inventories and the cost.

Not only the normal and emergency replenishments but also the production will be decided according to the stages of normal replenishment $z_{1}$ and $z_{2}$ by using tracking information.

At first, a production when the normal replenishment has not yet been released is begun if the following conditions have been satisfied.

- If the stage of the normal replenishment $\mathrm{z}_{1}$ is zero and the stage of the reduplicated normal replenishment $\mathrm{z}_{2}$ is zero.

$0 \leq \mathrm{x} \leq \mathrm{S}-1$ and $0 \leq \mathrm{y} \leq \mathrm{Y}$

When a normal replenishment has already been begun, a production is begun if the following conditions have been satisfied.

- If the stage of the normal replenishment $z_{1}$ is not zero and the stage of the reduplicated normal replenishment $\mathrm{z}_{2}$ is zero.

$0 \leq x \leq X-1$ and $0 \leq y \leq Y-S$ and $\left\{\begin{array}{l}z_{1} \geq g x+h y+i(g>0 \text { and } h \geq 0) \\ z_{1} \leq g x+h y+i(g<0 \text { and } h \leq 0)\end{array}\right.$

When a reduplicated normal replenishment has already been begun, a production is begun if the following conditions have been satisfied.

- If the stage of the normal replenishment $z_{1}$ is not zero and the stage of the reduplicated normal replenishment $\mathrm{z}_{2}$ is not zero.

$1 \leq x \leq X-1$ and $0 \leq y \leq Y-2 S$ and $z_{1}+z_{2} \geq j x+m y+n(j>0$ and $m \geq 0)$

\section{Markov Analysis}

For analyzing the performance of the proposed inventory control policy, a Markov chain model of the proposed inventory control policy is developed, and a performance measure is formulated in this section. 


\section{State Transition Diagram}

The state can be defined by the inventory on hand at the warehouse $\mathrm{x}$, the inventory at the retailer $y$, the stage of the normal replenishment $z_{1}$, and the stage of the reduplicated normal replenishment $\mathrm{z}_{2}$. Then, a state transition diagram of the Markov chain in the proposed policy is expressed as the four-dimensional space of $\left(\mathrm{x}, \mathrm{y}, \mathrm{z}_{1}, \mathrm{z}_{2}\right)$.

The state transitions within any stage caused by direct-channel customer arrival (at arrival rate $\lambda_{\mathrm{d}}$ ), retail-store-channel customer arrival (at arrival rate $\lambda_{\mathrm{r}}$ ), production (at production rate $\mu_{\mathrm{w}}$ ) and emergency replenishment (at replenishment rate $\mu_{\mathrm{r}}$ ) are shown in Figure 5.

When a demand arrives at rate $\lambda_{d}$ at the direct channel, the inventory of the warehouse decreases by one, and the state transitions from $\left(x, y, z_{1}, z_{2}\right)$ to $(x-1$, $\left.y, z_{1}, z_{2}\right)$. Similarly, when a demand arrives at rate $\lambda_{r}$ at the retail store channel, the inventory of the retail store decreases by one, and the state transitions from ( $x, y, z_{1}$, $\left.\mathrm{z}_{2}\right)$ to $\left(\mathrm{x}, \mathrm{y}-1, \mathrm{z}_{1}, \mathrm{z}_{2}\right)$. When production is done at production rate $\mu_{\mathrm{w}}$, the inventory of the warehouse increases by one, and the state transitions from $\left(x, y, z_{1}, z_{2}\right)$ to $(x+1$, $y, z_{1}, z_{2}$ ). When an emergency replenishment from the warehouse to the retail store is completed at replenishment rate $\mu_{\mathrm{r}}$, the inventory of the warehouse decreases by one and the inventory of the retail store increases by one, and the state transitions from $\left(\mathrm{x}, \mathrm{y}, \mathrm{z}_{1}, \mathrm{z}_{2}\right)$ to $\left(\mathrm{x}-1, \mathrm{y}+1, \mathrm{z}_{1}, \mathrm{z}_{2}\right)$.

The state transition of a normal replenishment between stages is caused by the start of the normal replenishment (at start rate $\mu_{\mathrm{R} 1}$ ), the progress of the normal replenishment (at progress rate $\mu_{\mathrm{R} 1}$ ) and the completion of the normal replenishment (at completion rate $\mu_{\mathrm{R} 1}$,), as shown in Figure 6.

Firstly, when the normal replenishment begins at starting rate $\mu_{\mathrm{R} 1}$ at the states of starting the normal replenishment, the state transitions from $(\mathrm{x}, \mathrm{y}, 0,0)$ to $(\mathrm{x}-\mathrm{S}, \mathrm{y}, 1,0)$. At this time, the inventory of the warehouse decreases by the lot size of normal replenishment $\mathrm{S}$. This shows that the warehouse and the retail store do not hold $\mathrm{S}$ products during a normal replenishment process until the replenishment is completed. Secondly, when the normal replenishment proceeds at progress rate $\mu_{\mathrm{R} 1}$, at the stage $(\mathrm{k}, 0)(0<\mathrm{k}<\mathrm{K})$, the state transitions from $(\mathrm{x}, \mathrm{y}, \mathrm{k}, 0)$ to $(\mathrm{x}, \mathrm{y}, \mathrm{k}+1,0)$. At this time, the inventory of the warehouse $x$ and the inventory of the retailer $y$ do not change. Finally, when the normal replenishment is completed at completion rate

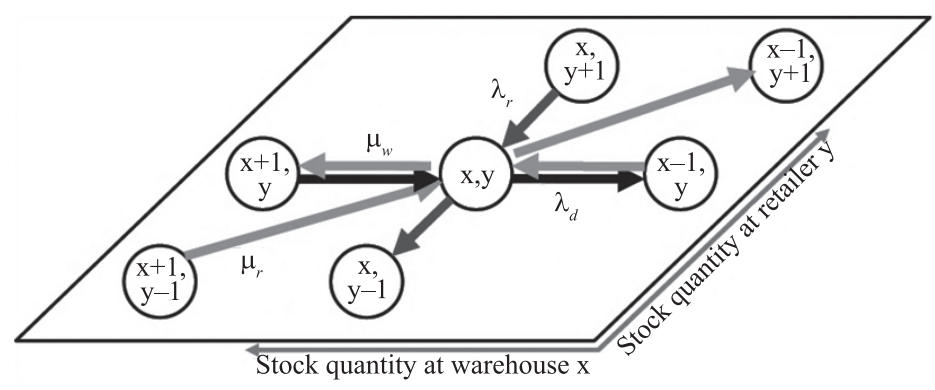

Figure 5. State transitions within a stage. 
$\mu_{\mathrm{R} 1}$, at the stage $(\mathrm{K}, 0)$, the state transitions from $(\mathrm{x}, \mathrm{y}, \mathrm{K}, 0)$ to $(\mathrm{x}, \mathrm{y}+\mathrm{S}, 0,0)$. At this time, the inventory of the retail store increases by the lot size of normal replenishment $\mathrm{S}$. This shows that the retail store receives $\mathrm{S}$ products and stocks them as inventory.

The state transition of a reduplicated normal replenishment between stages is caused by the start of the reduplicated normal replenishment (at starting rate $\mu_{\mathrm{R} 2}$ ), the progress of the reduplicated normal replenishment (at progress rates $\mu_{\mathrm{R} 2}$, and $\mu_{\mathrm{R} 2}$ "), and the completion of the normal replenishment (at completion rate $\mu_{\mathrm{R} 2}$, , ), as shown in Figure 7.

Firstly, when the reduplicated normal replenishment begins at start rate $\mu_{\mathrm{R} 2}$ at the states of starting the reduplicated normal replenishment at stage $\mathrm{k}^{\prime}\left(0<\mathrm{k}^{\prime}<\mathrm{K}+1\right)$, the state transitions from $\left(x, y, k^{\prime}, 0\right)$ to $\left(x-S, y, k^{\prime}, 1\right)$. At this time, the inventory of the warehouse decreases by the lot size of normal replenishment $\mathrm{S}$. This shows that the warehouse and the retail store do not hold S products during a normal replenishment process until the replenishment is completed. Secondly, in the process of the reduplicated

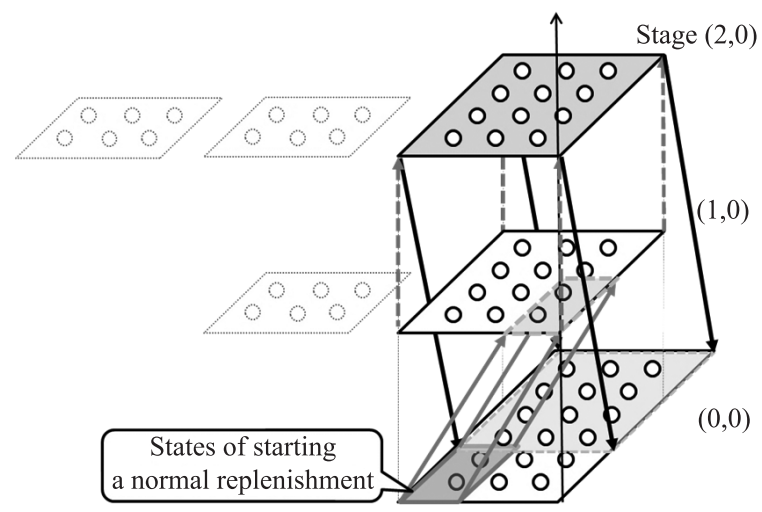

Figure 6. State transition of a normal replenishment.

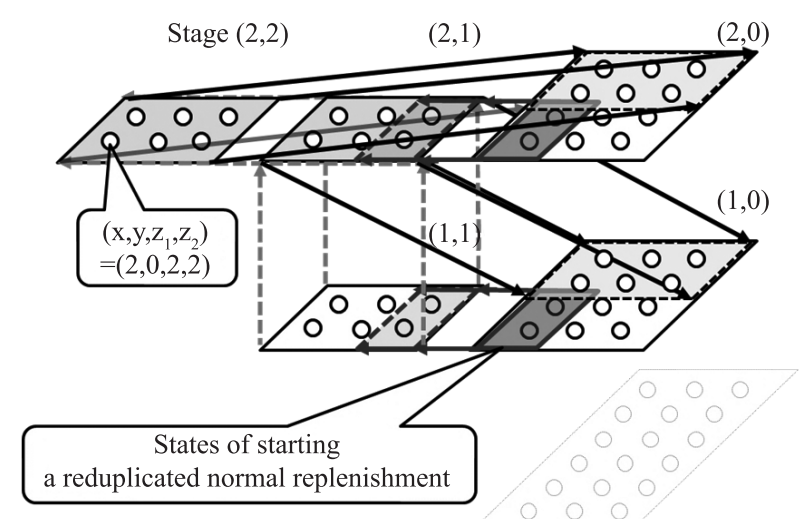

Figure 7. State transition of a reduplicated replenishment. 
normal replenishment, two normal replenishments have to be expressed at the same time. Therefore, the stage progresses to the upper stage and to the left stage. When one reduplicated normal replenishment proceeds, the stage goes to the upper stage (k", k"') $\left(0<\mathrm{k} "{ }^{\prime}<\mathrm{k}\right.$ " $\left.<\mathrm{K}\right)$ at progress rate $\mu_{\mathrm{R} 2}$, and the state transitions from $(\mathrm{x}, \mathrm{y}, \mathrm{k}$ ", $\mathrm{k}$ "') to $(\mathrm{x}, \mathrm{y}, \mathrm{k}$ " $+1, \mathrm{k}$ "'). When the other reduplicated normal replenishment proceeds, the stage goes to the left stage $\left(\mathrm{k}^{\prime \prime}, \mathrm{k}, ",\right)\left(0<\mathrm{k} ", \mathrm{k}^{\prime \prime},<\mathrm{K}\right)$ at progress rate $\mu_{\mathrm{R} 2}$, , and the state transitions from $(\mathrm{x}, \mathrm{y}, \mathrm{k}, ", \mathrm{k} "$,$) ) to (\mathrm{x}, \mathrm{y}, \mathrm{k} ", \mathrm{k}$ "," +1$)$. At this time, the inventory of the warehouse $x$ and the inventory of the retailer $y$ do not change. Finally, when the reduplicated normal replenishment is completed at completion rate $\mu_{\mathrm{R} 2}$,", at the stage $(\mathrm{K}$, $\mathrm{k}$ ), the inventory of the retail store increases by the lot size $\mathrm{S}$ of normal replenishment. This shows that the retail store receives $\mathrm{S}$ products and stocks them as inventory. Then, the state transitions from $(\mathrm{x}, \mathrm{y}, \mathrm{K}, \mathrm{k})$ to $(\mathrm{x}, \mathrm{y}+\mathrm{S} \mathrm{k}, 0)$.

Figure 8 shows the state transitions of the proposed policy.

\section{Flow Balance Equations}

Let $\pi_{\mathrm{xyz172} 2}$ be the steady-state probability of state $\left(\mathrm{x}, \mathrm{y}, \mathrm{z}_{1}, \mathrm{z}_{2}\right)$, and the state transitions from each state proposed above are expressed by the following flow balance equations.

$$
\begin{aligned}
\mathrm{A} \pi_{\mathrm{xyz}_{1} \mathrm{z}_{2}} & =\tau_{\mathrm{x}} \lambda_{\mathrm{d}} \pi_{(\mathrm{x}+1) \mathrm{yz}_{1} \mathrm{z}_{2}}+\tau_{\mathrm{y}} \lambda_{\mathrm{r}} \pi_{\mathrm{x}(\mathrm{y}+1) \mathrm{z}_{1} \mathrm{z}_{2}}+\tau_{\mathrm{x}}^{\mathrm{w}} \mu_{\mathrm{w}} \pi_{(\mathrm{x}-1) \mathrm{yz}_{1} \mathrm{z}_{2}} \\
& +\tau_{\mathrm{x}}^{\mathrm{w}^{\prime}} \mu_{\mathrm{w}} \pi_{(\mathrm{x}-1) \mathrm{yz}_{1} \mathrm{z}_{2}}+\tau_{\mathrm{x}}^{\mathrm{w}^{\prime \prime}} \mu_{\mathrm{w}} \pi_{(\mathrm{x}-1) \mathrm{yz}_{1} \mathrm{z}_{2}}+\tau_{\mathrm{xyz}_{1} \mathrm{z}_{2}}^{\mathrm{r}} \mu_{\mathrm{R} 1} \pi_{(\mathrm{x}+S) \mathrm{y}\left(\mathrm{z}_{1}-1\right) \mathrm{z}_{2}} \\
& +\tau_{\mathrm{z}_{1} \mathrm{z}_{2}} \mu_{\mathrm{R} 1^{\prime}} \pi_{\mathrm{xy}\left(\mathrm{z}_{1}-1\right) \mathrm{z}_{2}}+\tau_{\mathrm{z}_{1} \mathrm{z}_{2}}^{\prime} \mu_{\mathrm{R} 1^{\prime \prime}} \pi_{\mathrm{x}(\mathrm{y}-S)\left(\mathrm{z}_{1}+\mathrm{K}\right) \mathrm{z}_{2}}+\rho_{\mathrm{xyz}_{1} \mathrm{z}_{2}} \mu_{\mathrm{r}} \pi_{(\mathrm{x}+1)(\mathrm{y}-1) \mathrm{z}_{1} \mathrm{z}_{2}} \\
& +\theta_{\mathrm{xyz}_{1} \mathrm{z}_{2}} \mu_{\mathrm{R} 2} \pi_{(\mathrm{x}+S) \mathrm{yz} \mathrm{z}_{1}\left(\mathrm{z}_{2}-1\right)}+\sigma_{\mathrm{z}_{1} \mathrm{z}_{2}} \mu_{\mathrm{R} 2^{\prime}} \pi_{\mathrm{xy}\left(\mathrm{z}_{1}-1\right) \mathrm{z}_{2}}+\xi_{\mathrm{z}_{1} \mathrm{z}_{2}} \mu_{\mathrm{R} 2^{\prime \prime}} \pi_{\mathrm{xyz}_{1}\left(\mathrm{z}_{2}-1\right)} \\
& +\psi_{\mathrm{z}_{1} \mathrm{z}_{2}} \mu_{\mathrm{R} 2}{ }^{\prime \prime} \pi_{\mathrm{x}(\mathrm{y}-S) \mathrm{Kz}_{1}}
\end{aligned}
$$

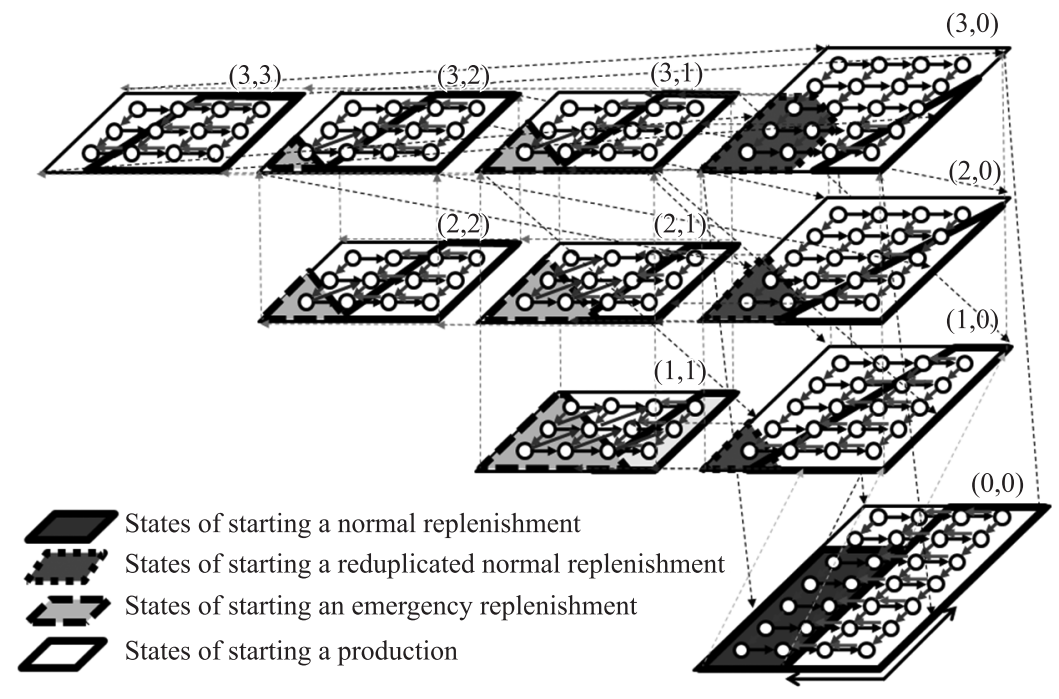

Figure 8. State transitions of the proposed policy. 
Here,

$$
\begin{aligned}
\mathrm{A} & =\chi_{\mathrm{x}} \lambda_{\mathrm{d}}+\delta_{\mathrm{y}} \lambda_{\mathrm{r}}+\epsilon_{\mathrm{xyz}_{1} \mathrm{z}_{2}} \mu_{\mathrm{w}}+\epsilon_{\mathrm{xyz}_{1} \mathrm{z}_{2}}^{\prime} \mu_{\mathrm{w}}+\epsilon_{\mathrm{xyz}_{1} \mathrm{z}_{2}}^{\prime \prime} \mu_{\mathrm{w}}+\phi_{\mathrm{xyz}_{1} \mathrm{z}_{2}} \mu_{\mathrm{R} 1} \\
& +\varphi_{\mathrm{z}_{1} \mathrm{z}_{2}} \mu_{\mathrm{R} 1^{\prime}}+\gamma_{\mathrm{z}_{1} \mathrm{z}_{2}} \mu_{\mathrm{R} 1^{\prime \prime}}+\eta_{\mathrm{xyz}_{1} \mathrm{z}_{2}} \mu_{\mathrm{r}}+\kappa_{\mathrm{xyz}_{1} \mathrm{z}_{2}} \mu_{\mathrm{R} 2}+v_{\mathrm{z}_{1} \mathrm{z}_{2}} \mu_{\mathrm{R} 2} \\
& +\mathrm{o}_{\mathrm{z}_{1} \mathrm{z}_{2}} \mu_{\mathrm{R} 2^{\prime \prime}}+\omega_{\mathrm{z}_{1} \mathrm{z}_{2}} \mu_{\mathrm{R} 2^{\prime \prime \prime}}
\end{aligned}
$$

Also, in the equations, the following $0-1$ variables that show the conditions in Equations 1-6 are used. The 0-1 variables $\phi_{\mathrm{xyz}_{1} z_{2}}$ and $\tau_{\mathrm{xyz}_{1} z_{2}}^{\mathrm{r}}$ show the condition in Equation 1. Also, the 0-1 variables $\kappa_{\mathrm{xyz}_{1} z_{2}}$ and $\theta_{\mathrm{xyz}_{1} z_{2}}$ show that in Equation $2, \eta_{\mathrm{xyz}_{1} z_{2}}$ and $\rho_{\mathrm{xyz}_{1} z_{2}}$ that in Equation 3, $\epsilon_{\mathrm{xyz}_{1} z_{2}}$ and $\tau_{\mathrm{xyz}_{1} z_{2}}^{\mathrm{w}}$ that in Equation 4, $\epsilon_{\mathrm{xyz}_{1} \mathrm{z}_{2}}^{\prime}$ and $\tau_{\mathrm{xyz}_{1} z_{2}}$ that in Equation 5, $\epsilon^{\prime \prime}{ }_{\mathrm{xyz}_{1} z_{2}}$ and $\tau_{\mathrm{xyz}_{1} \mathrm{z}_{2}}$ that in Equation 6 . The others are for showing the conditions where each transition can be considered at the current state.

$$
\begin{aligned}
& \chi_{\mathrm{x}}=\left\{\begin{array}{l}
0 \text { if } \mathrm{x}=0 \\
1 \text { otherwise }
\end{array}\right. \\
& \delta_{\mathrm{y}}=\left\{\begin{array}{l}
0 \text { if } \mathrm{y}=0 \\
1 \text { otherwise }
\end{array}\right.
\end{aligned}
$$

$\epsilon_{\mathrm{xyz}_{1} \mathrm{z}_{2}}=\left\{\begin{array}{l}1 \text { if } 0 \leq \mathrm{x} \leq \mathrm{S}-1 \text { and } 0 \leq \mathrm{y} \leq \mathrm{Y} \text { and } \mathrm{z}_{1}=\mathrm{z}_{2}=0 \\ 0 \text { otherwise }\end{array}\right.$

$$
\epsilon_{\mathrm{xyz}_{1} z_{2}}^{\prime}=\left\{\begin{array}{l}
1 \text { if } 0 \leq \mathrm{x} \leq \mathrm{X}-1 \text { and } 0 \leq \mathrm{y} \leq \mathrm{Y}-\mathrm{S} \\
\text { and }\left\{\begin{array}{l}
\mathrm{z}_{1} \geq \mathrm{gx}+\mathrm{hy}+\mathrm{i}(\mathrm{g}>0 \text { and } \mathrm{h} \geq 0) \\
\mathrm{z}_{1} \geq \mathrm{gx}+\mathrm{hy}+\mathrm{i}(\mathrm{g}<0 \text { and } \mathrm{h} \leq 0)
\end{array}\right. \\
\text { and } \mathrm{z}_{1} \neq 0 \text { and } \mathrm{z}_{2}=0 \\
0 \text { otherwise }
\end{array}\right.
$$

$$
\epsilon_{\mathrm{xyz}_{1} z_{2}}^{\prime \prime}=\left\{\begin{array}{l}
1 \text { if } 1 \leq \mathrm{x} \leq \mathrm{X}-1 \text { and } 0 \leq \mathrm{y} \leq \mathrm{Y}-2 \mathrm{~S} \\
\text { and } \mathrm{z}_{1}+\mathrm{z}_{2} \leq \mathrm{jx}+\mathrm{my}+\mathrm{n}(\mathrm{j} \geq 0 \text { and } \mathrm{m} \geq 0) \\
\text { and } \mathrm{z}_{1} \neq 0 \text { and } \mathrm{z}_{2} \neq 0 \\
0 \text { otherwise }
\end{array}\right.
$$

$\phi_{\mathrm{xyz}_{1} \mathrm{z}_{2}}=\left\{\begin{array}{l}1 \text { if } S \leq \mathrm{x} \leq \mathrm{X} \text { and } 0 \leq \mathrm{y} \leq \mathrm{Y}-\mathrm{S} \text { and } \mathrm{z}_{1}=\mathrm{z}_{2}=0 \\ 0 \text { otherwise }\end{array}\right.$

$\varphi_{z_{1} z_{2}}=\left\{\begin{array}{l}1 \text { if } 0<z_{1}<\text { Kand } z_{2}=0 \\ 0 \text { otherwise }\end{array}\right.$ 
$\gamma_{z_{1} z_{2}}=\left\{\begin{array}{l}1 \text { if } z_{1}=\text { Kand } z_{2}=0 \\ 0 \text { otherwise }\end{array}\right.$

$\eta_{\mathrm{xyz}_{1} \mathrm{z}_{2}}=\left\{\begin{array}{l}1 \text { if } 1 \leq \mathrm{x} \leq \mathrm{X} \text { and } 0 \leq \mathrm{y} \leq \mathrm{Y}-2 \mathrm{~S}-1 \\ \text { and } \mathrm{z}_{1}+\mathrm{z}_{2} \leq \mathrm{dx}+\mathrm{ey}+\mathrm{f}(\mathrm{d} \geq 0 \text { and } \mathrm{e}<0) \\ \text { and } \mathrm{z}_{1} \neq 0 \text { and } \mathrm{z}_{2} \neq 0 \\ 0 \text { otherwise }\end{array}\right.$

$\kappa_{\mathrm{xyz}_{1} \mathrm{z}_{2}}=\left\{\begin{array}{l}1 \text { if } S \leq \mathrm{x} \leq \mathrm{X} \text { and } 0 \leq \mathrm{y} \leq \mathrm{Y}-2 \mathrm{~S} \\ \text { and }\left\{\begin{array}{l}\mathrm{z}_{1} \leq \mathrm{ax}+\mathrm{by}+\mathrm{c}(\mathrm{a} \geq 0 \text { and } \mathrm{b}<0) \\ \mathrm{z}_{1} \geq \mathrm{ax}+\mathrm{by}+\mathrm{c}(\mathrm{a} \leq 0 \text { and } \mathrm{b}>0)\end{array}\right. \\ \text { and } \mathrm{z}_{1} \neq 0 \text { and } \mathrm{z}_{2}=0 \\ 0 \text { otherwise }\end{array}\right.$

$v_{z_{1} z_{2}}=\left\{\begin{array}{l}1 \text { if } 0<z_{1}<\text { Kand } z_{2} \neq 0 \\ 0 \text { otherwise }\end{array}\right.$

$o_{z_{1} z_{2}}=\left\{\begin{array}{l}1 \text { if } 0<z_{2}<z_{1} \\ 0 \text { otherwise }\end{array} \omega_{z_{1} z_{2}}=\left\{\begin{array}{l}1 \text { if } z_{1}=\text { Kand } z_{2} \neq 0 \\ 0 \text { otherwise }\end{array}\right.\right.$

$\tau_{\mathrm{x}}=\left\{\begin{array}{l}0 \text { if } \mathrm{x}=\mathrm{X} \\ 1 \text { otherwise }\end{array}\right.$

$\tau_{\mathrm{y}}=\left\{\begin{array}{l}0 \text { if } \mathrm{y}=\mathrm{Y} \\ 1 \text { otherwise }\end{array}\right.$

$\tau_{\mathrm{xyz}_{1} \mathrm{z}_{2}}^{\mathrm{w}}=\left\{\begin{array}{l}1 \text { if } 1 \leq \mathrm{x} \leq \mathrm{S} \text { and } 0 \leq \mathrm{y} \leq \mathrm{Y} \text { and } \mathrm{z}_{1}=1 \text { and } \mathrm{z}_{2}=0 \\ 0 \text { otherwise }\end{array}\right.$

$$
\tau_{\mathrm{xyz}_{1} \mathrm{z}_{2}}^{\mathrm{w}^{\prime}}=\left\{\begin{array}{l}
1 \text { if } 1 \leq \mathrm{x} \leq \mathrm{X} \text { and } 0 \leq \mathrm{y} \leq \mathrm{Y}-\mathrm{S} \\
\text { and }\left\{\begin{array}{l}
\mathrm{z}_{1} \geq \mathrm{g}(\mathrm{x}-1)+\mathrm{hy}+\mathrm{i}(\mathrm{g}>0 \text { and } \mathrm{h} \geq 0) \\
\mathrm{z}_{1} \geq \mathrm{g}(\mathrm{x}-1)+\mathrm{hy}+\mathrm{i}(\mathrm{g}<0 \text { and } \mathrm{h} \leq 0)
\end{array}\right. \\
\text { and } \mathrm{z}_{1} \neq 0 \text { and } \mathrm{z}_{2}=1 \\
0 \text { otherwise }
\end{array}\right.
$$




$$
\tau_{\mathrm{xyz}_{1} \mathrm{z}_{2}}^{\mathrm{w}^{\prime \prime}}=\left\{\begin{array}{l}
1 \text { if } 2 \leq \mathrm{x} \leq \mathrm{X} \text { and } 0 \leq \mathrm{y} \leq \mathrm{Y}-2 \mathrm{~S} \\
\operatorname{and} \mathrm{z}_{1}+\mathrm{z}_{2} \leq \mathrm{j}(\mathrm{x}-1)+\mathrm{my}+\mathrm{n}(\mathrm{j} \geq 0 \text { and } \mathrm{m} \geq 0) \\
\text { and } \mathrm{z}_{1} \neq 0 \text { and } \mathrm{z}_{2} \neq 0 \\
0 \text { otherwise }
\end{array}\right.
$$

$\tau_{\mathrm{xyz}_{1} \mathrm{z}_{2}}^{\mathrm{r}}=\left\{\begin{array}{l}1 \text { if } 0 \leq \mathrm{x} \leq \mathrm{X}-\mathrm{S} \text { and } 0 \leq \mathrm{y} \leq \mathrm{Y}-\mathrm{S} \text { and } \mathrm{z}_{1}=1 \text { and } \mathrm{z}_{2}=0 \\ 0 \text { otherwise }\end{array}\right.$

$\tau_{z_{1} z_{2}}=\left\{\begin{array}{l}1 \text { if } 1<z_{1} \leq \text { Kand } z_{2}=0 \\ 0 \text { otherwise }\end{array}\right.$

$$
\tau_{z_{1} z_{2}}^{\prime}=\left\{\begin{array}{l}
1 \text { if } z_{1}=0 \text { and } z_{2}=0 \\
0 \text { otherwise }
\end{array}\right.
$$

$\rho_{\mathrm{xyz}_{1} z_{2}}=\left\{\begin{array}{l}1 \text { if } 0 \leq x \leq X-1 \text { and } 0 \leq y \leq Y-2 S \\ \text { and } z_{1}+z_{2} \leq d(x+1)+e(y-1)+f(d \geq 0 \text { and } e<0) \\ \text { and } z_{1} \neq 0 \text { and } z_{2} \neq 0 \\ 0 \text { otherwise }\end{array}\right.$

$\theta_{\mathrm{xyz}_{1} \mathrm{z}_{2}}=\left\{\begin{array}{l}\text { iff } 0 \leq \mathrm{x} \leq \mathrm{X}-\text { Sand } 0 \leq \mathrm{y} \leq \mathrm{Y}-2 \mathrm{~S} \\ \text { and }\left\{\begin{array}{l}\mathrm{z}_{1} \leq \mathrm{a}(\mathrm{x}+\mathrm{S})+\mathrm{by}+\mathrm{c}(\mathrm{a} \geq 0 \text { and } \mathrm{b}<0) \\ \mathrm{z}_{1} \geq \mathrm{a}(\mathrm{x}+\mathrm{S})+\mathrm{by}+\mathrm{c}(\mathrm{a} \leq 0 \text { and } \mathrm{b}>0)\end{array}\right. \\ \text { and } \mathrm{z}_{1} \neq 0 \text { and } \mathrm{z}_{2}=1 \\ \text { 0 otherwise }\end{array}\right.$

$\sigma_{z_{1} z_{2}}=\left\{\begin{array}{l}1 \text { if } 1<z_{1} \leq K \text { and } z_{2} \neq 0 \\ 0 \text { otherwise }\end{array}\right.$

$\zeta_{z_{1} z_{2}}=\left\{\begin{array}{l}1 \text { if } 1<z_{2}<z_{1} \\ 0 \text { otherwise }\end{array}\right.$

$\psi_{z_{1} z_{2}}=\left\{\begin{array}{l}1 \text { if } z_{1} \neq 0 \text { and } z_{2}=0 \\ 0 \text { otherwise }\end{array}\right.$

The above flow balance equations and the following equation are utilized to solve the steady-state probability of each state. 
$\sum_{x=0 y=0 z_{1}=0 z_{2}=0}^{X} \sum_{x_{1}}^{K} \sum_{z_{1} z_{2}}^{K}=1$

\section{Performance Measure}

As a performance measure, the total cost $\mathrm{TC}$, which consists of the inventory holding $\operatorname{cost} \mathrm{C}_{\mathrm{H}}$, the shortage $\operatorname{cost} \mathrm{C}_{\mathrm{L}}$, the emergency replenishment $\cos t \mathrm{C}_{\mathrm{ER}}$, and the tracking information $\operatorname{cost} \mathrm{C}_{\mathrm{T}}$, is formulated. The steady-state probability $\pi_{\mathrm{xyzlz2}}$ of each state is calculated by solving the flow balance equations as a set of simultaneous equations. Then, $\mathrm{C}_{\mathrm{H}}, \mathrm{C}_{\mathrm{L}}, \mathrm{C}_{\mathrm{ER}}$, and $\mathrm{C}_{\mathrm{TI}}$ are calculated as follows with the calculated $\pi_{\mathrm{xyz} z \mathrm{z} 2}$.

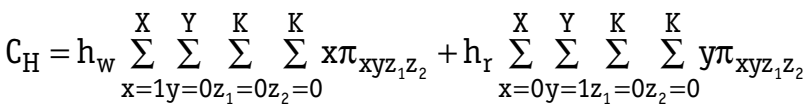

$$
\begin{aligned}
& \mathrm{C}_{\mathrm{L}}=\mathrm{l} \sum_{\mathrm{y}=1 \mathrm{z}_{1}=0 \mathrm{z}_{2}=0}^{\mathrm{Y}} \sum_{0 \mathrm{yz}_{1} \mathrm{z}_{2}}^{\mathrm{K}} \lambda_{\mathrm{d}}+\mathrm{l} \sum_{\mathrm{x}=1 \mathrm{z}_{1}=0 \mathrm{z}_{2}=0}^{\mathrm{X}} \sum_{\sum_{1}}^{\mathrm{K}} \pi_{\mathrm{x} 0 \mathrm{z}_{1} \mathrm{z}_{2}} \lambda_{\mathrm{r}}+\mathrm{l} \sum_{\mathrm{z}_{1}=0 \mathrm{z}_{2}=0}^{\mathrm{K}} \sum_{00 \mathrm{z}_{1} \mathrm{z}_{2}}^{\mathrm{K}}\left(\lambda_{\mathrm{d}}+\lambda_{\mathrm{r}}\right) \\
& C_{E S}=e s \sum_{x=d+f y=0 z_{1}=1 z_{2}=1}^{X} \sum_{x y z_{1} z_{2}}^{e+f} \mu_{r} \\
& \mathrm{C}_{\mathrm{TI}}=\mathrm{ti} \sum_{\mathrm{k}=2}^{\mathrm{K}+1} \mathrm{k}
\end{aligned}
$$

Here, $h_{w}$ is the unit inventory holding cost at the warehouse, $h_{r}$ is the unit inventory holding cost at the retail store, 1 is the unit shortage cost, es is the unit emergency replenishment cost, and ti is the unit tracking information cost. TC is formulated as follows.

$$
\mathrm{TC}=\mathrm{C}_{\mathrm{H}}+\mathrm{C}_{\mathrm{L}}+\mathrm{C}_{\mathrm{ER}}+\mathrm{C}_{\mathrm{TI}}
$$

\section{Numerical Experiments}

The effectiveness of the proposed policy was evaluated by comparing the least total costs of the proposed policy and two alternative policies, one without tracking information and the other without reduplicated normal replenishment.

\section{Alternative Policies}

Alternative Policy 1 uses reduplicated normal replenishment but not tracking information. In this policy, the progress of replenishment is never tracked. Therefore, the start of a reduplicated normal replenishment and the start of an emergency replenishment do not depend on stages $z_{1}$ or $z_{2}$, as shown in Figure 9.

In Alternative Policy 1, an emergency replenishment is ordered if the following condition is satisfied: 
$(3,0)$

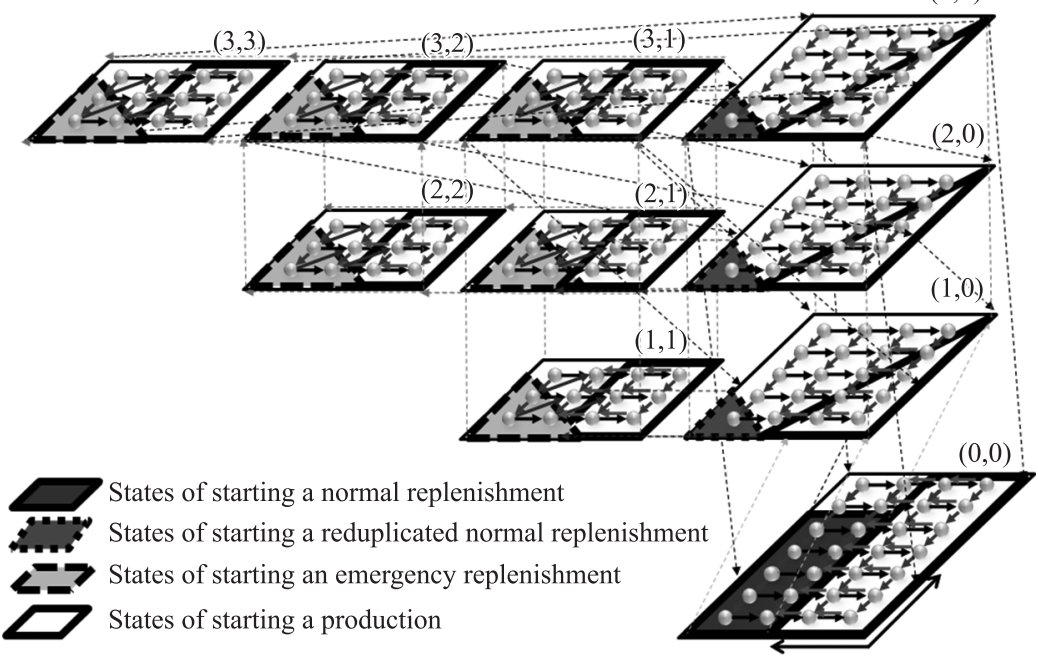

Figure 9. State transitions of Alternative Policy 1.

$y \leq q^{\prime} x+r^{\prime}\left(q^{\prime} \geq 0\right)$

Similarly, a reduplicated normal replenishment is ordered if the following condition is satisfied:

$y \leq q^{\prime \prime} x+r^{\prime \prime}\left(q^{\prime \prime} \geq 0\right)$

Alternative Policy 2 uses tracking information but not reduplicated normal replenishment. In this policy, a normal replenishment is not ordered unless the previous normal replenishment has been completed. Then, stage $z_{1}$ is always zero. Moreover, in this policy, the start of an emergency replenishment does not depend on stage $z_{2}$, as shown in Figure 10.

In Alternative Policy 2, an emergency replenishment is ordered if the following condition is satisfied:

$$
z_{1} \geq s^{\prime} x+t^{\prime} y+u^{\prime}\left(s^{\prime} \geq 0 \text { and } t^{\prime}<0\right)
$$

\section{Experimental Conditions}

As key factors that have much influence upon the performance of the proposed policy, the unit emergency replenishment cost es $(=50,100, \ldots, 500)$, the unit tracking information cost ti $(=10,20, \ldots, 90)$, the normal replenishment rate $\mu_{\mathrm{R}}$ $(=1,1,5, \ldots, 10)$ and the emergency replenishment rate $\mu_{\mathrm{r}}(=10,15, \ldots, 100)$ are considered in the numerical experiments. In calculating the influence of the factors, the other factors are fixed as follows: $\lambda=15, \alpha=0.45, \mu_{\mathrm{w}}=30, \mu_{\mathrm{R} 1}=\mu_{\mathrm{R} 2}=100$, $\mu_{\mathrm{R} 1},=\mu_{\mathrm{R} 1},=\mu_{\mathrm{R} 2},=\mu_{\mathrm{R} 2},=\mu_{\mathrm{R} 2},=2, \mu_{\mathrm{r}}=50,1=100, \mathrm{~h}_{\mathrm{w}}=50, \mathrm{~h}_{\mathrm{r}}=80$, es $=300$, and $\mathrm{ti}=10$. 

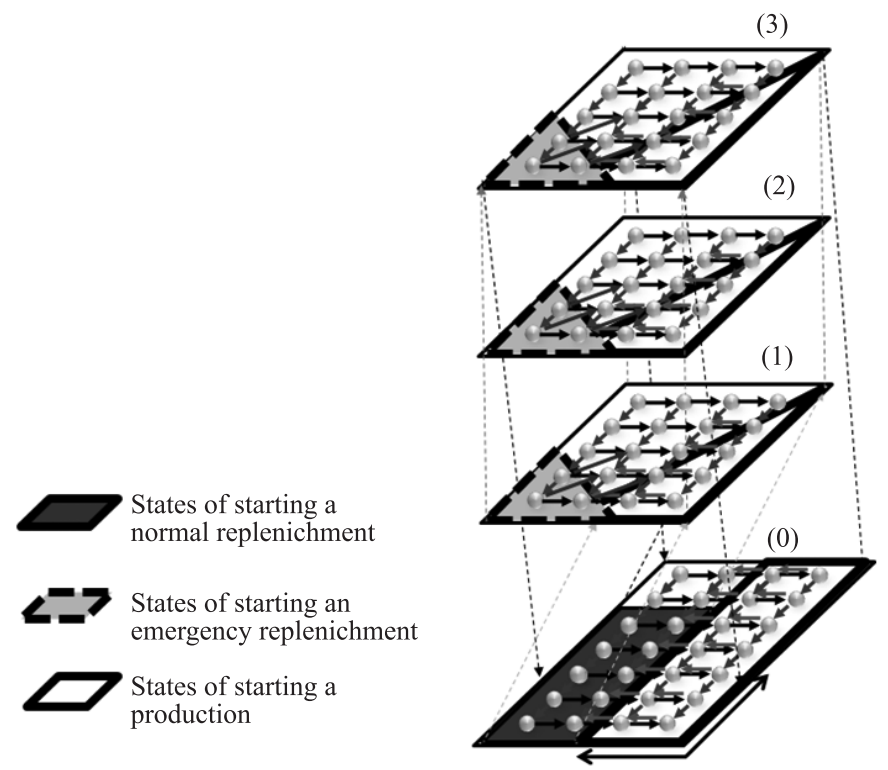

Figure 10. State transitions of Alternative Policy 2.

The least total cost of the proposed policy is obtained by calculating the total costs under $\mathrm{X}=2,3,4, \mathrm{Y}=4, \ldots, 8, \mathrm{~S}=2,3,4, \mathrm{a}=-1,0,1, \mathrm{~b}=-1,1, \mathrm{c}=-5$, $-4, \ldots, 5, \mathrm{~d}=0,0.5, \mathrm{e}=-1, \mathrm{f}=-5,-4, \ldots, 5, \mathrm{~g}=-1,1, \mathrm{~h}=-0.5,0,0, \mathrm{i}=-5,-4, \ldots, 5$, $\mathrm{j}=1, \mathrm{~m}=0,0.5$, and $\mathrm{n}=-5,-4, \ldots, 5$. Also, the least total cost of Alternative Policy 1 is obtained by calculating the total costs under $\mathrm{X}=2, \ldots, 4, \mathrm{Y}=4, \ldots, 8, \mathrm{~S}=2, \ldots$, $4, \mathrm{q}^{\prime}=0,0.1, \ldots, 1, \mathrm{r}^{\prime}=-10,-9, \ldots, 10, \mathrm{q} "=0,0.1, \ldots, 1$, and $\mathrm{r}^{\prime \prime}=-10,-9, \ldots, 10$. The least total cost of Alternative Policy 2 is obtained by calculating the total costs under $\mathrm{X}=2, \ldots, 4, \mathrm{Y}=4, \ldots, 8, \mathrm{~S}=2, \ldots, 4, \mathrm{~s}^{\prime}=0,0.1, \ldots, 1, \mathrm{t}^{\prime}=-1,-0.9, \ldots, 0$, and $\mathrm{u}^{\prime}=-10,-9, \ldots, 10$.

\section{Results and Discussion}

As results of numerical experiments, two kinds of results will be shown.

At first, the influences of unit emergency replenishment cost es and unit tracking cost ti upon the least total cost of each policy are shown as in Figure 11.

Figure 11 shows that the total cost of the proposed policy is much less than those of the alternative policies, especially for the lower ti (that is, for the lower unit tracking information cost) and the higher es (that is, for the higher unit emergency replenishment cost). Therefore, it can be claimed that the proposed policy is effective when the tracking cost is low and the emergency replenishment cost is high. Moreover, the influences of unit emergency cost es on the total cost of each policy are not small for a small unit tracking information cost ti.

Figure 12 shows the influence of the unit tracking information cost on each component of the total cost for es $=50$, and Figure 13 shows the influence of unit emergency replenishment cost on each component of the total cost for $\mathrm{ti}=10$. 
Figures 12 and 13 show the cause of the results in Figure 11. In the figures, Figure 12 shows the influence of unit tracking information cost on each component of the total cost, and the proposed policy and Alternative Policy 2 cannot reduce not only the cost of tracking information but also the other costs significantly from that of Alternative Policy 1 when the unit tracking information cost increases. When the unit tracking information cost is high, we may try to save the cost by reducing the number of tracking stages. However, in this paper, the number of tracking stages is not considered as a decision variable, and the increase in the unit tracking information cost affects the increase in the cost and the total cost in the policies that use the tracking information. Then, the effectiveness of using tracking information decreases when the tracking information cost per unit increases.

In addition, Figure 13 shows the influence of unit emergency replenishment cost on each component of the total cost, and the proposed policy and Alternative Policy 2 can reduce the cost of emergency replenishment significantly from that of Alternative
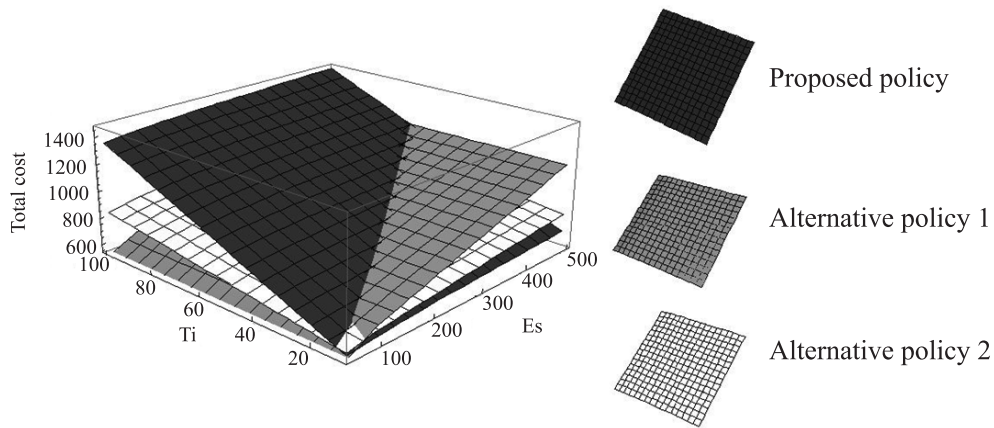

Figure 11. The influences of unit tracking cost ti and unit emergency replenishment cost es on the least total cost of each policy.

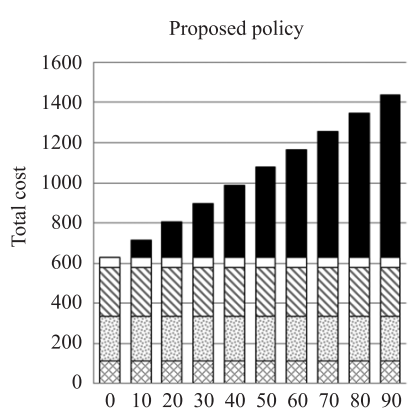

$\mathrm{Ti}$

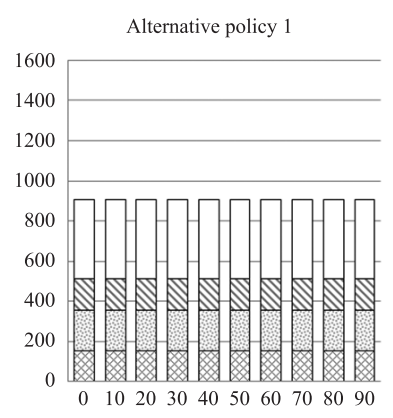

$\mathrm{Ti}$

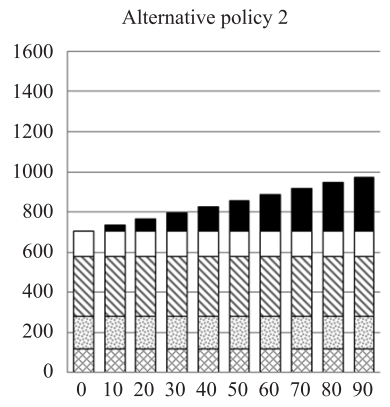

$\mathrm{Ti}$

$\mathbb{N}$ Shortage cost $\square$ Emergency replenishment cost

Holding cost (retailer)

Figure 12. The influence of the unit tracking information cost on each component of the total cost for es $=50$. 
Policy 1 when the unit emergency replenishment cost increases. In the propose policy and Alternative Policy 2, the cost of emergency replenishment can be reduced by using tracking information, or the increase in the unit emergency replenishment cost means the relative decrease in the unit tracking information cost. Therefore, the effectiveness of using tracking information increases when the unit emergency replenishment cost increases or the tracking information cost per unit decreases.

Secondly, the influences of the two kinds of lead time of replenishment on the total costs of the three policies are shown in Figure 14. The lead time of normal

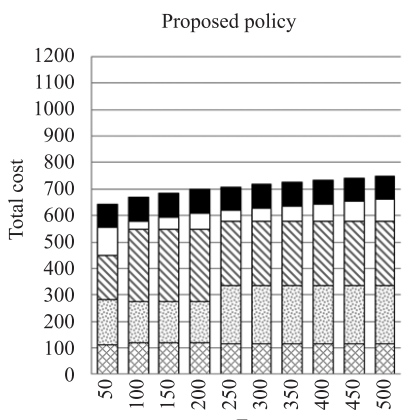

Es

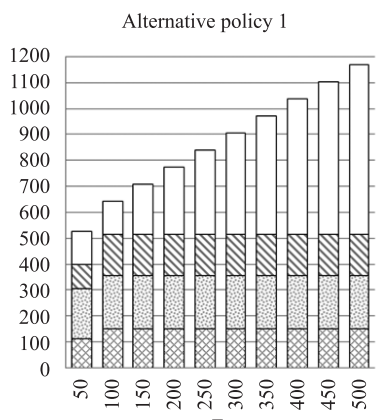

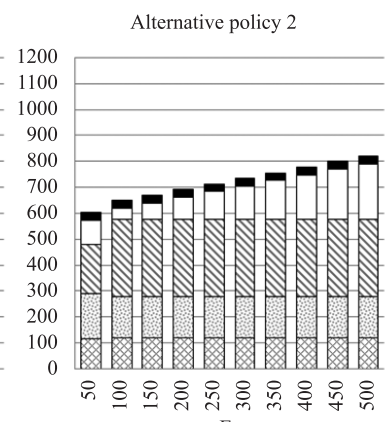

Es

$\mathbb{N}$ Shortage cost $\square$ Emergency replenishment cost $\quad$ Tracking irformation cost

Figure 13. The influence of the unit emergency replenishment cost on each component of the total cost for $\mathrm{ti}=10$.
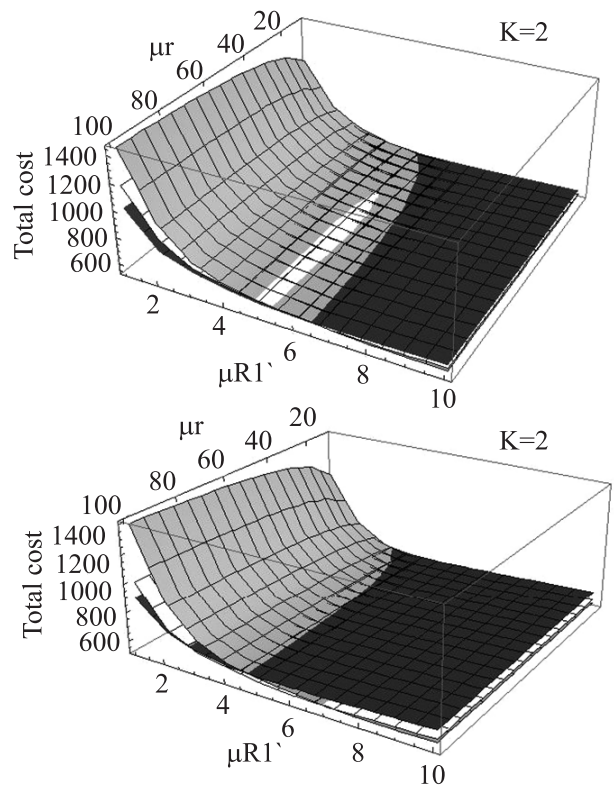

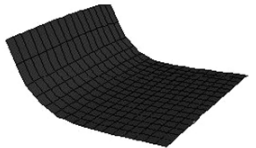

Proposed policy

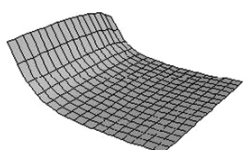

Alternative policy 1

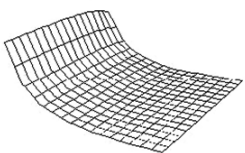

Alternative policy 2

Figure 14. Influence of the lead time of replenishment on the total costs of the three policies. 
replenishment is the sum of the reciprocals of transition rates $\mu_{\mathrm{R} 1}, \mu_{\mathrm{R} 1}$, and $\mu_{\mathrm{R} 1}$,. The start rate $\mu_{\mathrm{R} 1}$ of normal replenishment does not affect the total cost because a replenishment is ordered immediately. That is, the influence of the lead time of normal replenishment on the total cost can be shown by the influence of progress rate $\mu_{\mathrm{R} 1}$, and completion rate $\mu_{\mathrm{R} 1}$, on the total cost. However, only the influence of $\mu_{\mathrm{R} 1}$, is shown because $\mu_{\mathrm{R} 1}$, and $\mu_{\mathrm{R} 1}$, are the same. Moreover, the lead time of emergency replenishment is given by the reciprocal of transition rate $\mu_{r}$. Therefore, the influence of the lead time of emergency replenishment on the total cost can be shown by the influence of replenishment rate $\mu_{\mathrm{r}}$ on the total cost.

Figure 14 shows that the total cost of the proposed policy is much less than those of the alternative policies, especially for the lower $\mu_{\mathrm{R} 1}$, (that is, for the long lead time of normal replenishment). Therefore, it can be claimed that the proposed policy is effective when the lead time of normal replenishment is long. Moreover, the influences of the lead time $\mathrm{L}_{\mathrm{r}}$ of emergency replenishment on the total cost of each policy are not small for a long lead time $\mathrm{L}_{\mathrm{R}}$ of normal replenishment.

Figure 15 shows the total cost reduction rate of the proposed policy from the alternative policies.

As shown in Figure 15, the reduction rate of the proposed policy is positive for a low $\mu_{\mathrm{R} 1}$. When the lead time of normal replenishment is long, the total cost reduction rate of the proposed policy from Alternative Policy 1 is larger than that from Alternative Policy 2. For $\mu_{\mathrm{R} 1}=1$ and $\mu_{\mathrm{r}}=100$, the reduction rate from Alternative Policy 1 is about $30 \%$. In contrast, the reduction rate from Alternative Policy 2 is about $14 \%$. Thus, when the lead time of normal replenishment is long, the effectiveness of tracking information and reduplicated replenishment is high (the effectiveness of tracking information is particularly high).

However, when the lead time of normal replenishment is short, the total cost reduction rate of the proposed policy from Alternative Policy 1 is lower than that from Alternative Policy 2. For $\mu_{\mathrm{R} 1}=10$ and $\mu_{\mathrm{r}}=100$, the reduction rate from Alternative Policy 1 is about $-8 \%$. In contrast, the reduction rate from Alternative Policy 2 is about $-4 \%$. Thus, when the lead time of normal replenishment is short, the effectiveness of tracking information and reduplicated replenishment is low (the effectiveness of tracking information is particularly low).

In addition, Figure 15 shows that the influence of the lead time of emergency replenishment is great when the lead time of normal replenishment is long. For $\mu_{\mathrm{R} 1}=1$
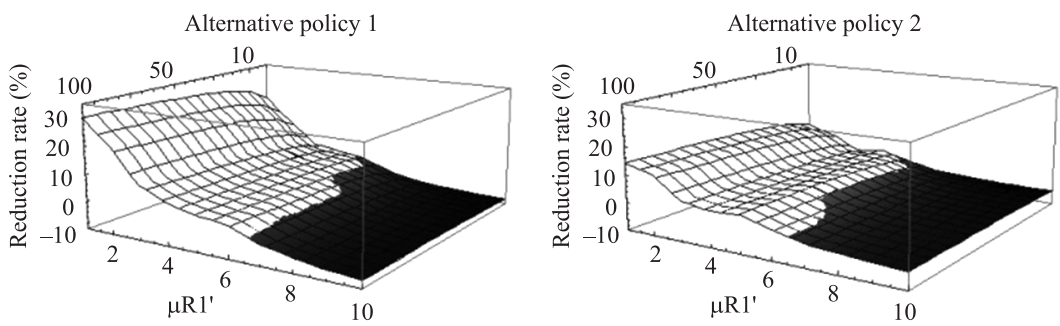

Figure 15. Total cost reduction rate of the proposed policy from the alternative policies. 
and $\mu_{\mathrm{r}}=100$, the reduction rate from Alternative Policy 1 is about $30 \%$. For $\mu_{\mathrm{R} 1}=1$ and $\mu_{\mathrm{r}}=10$, the reduction rate from Alternative Policy 1 is about $20 \%$. Thus, when the lead time of normal replenishment is long, the effectiveness of tracking information is affected by the length of the lead time of emergency replenishment.

Figure 16 shows the influence of the lead time of normal replenishment on each component of the total cost for $\mu_{\mathrm{r}}=10$.

Figure 16 shows the cause of the results in Figure 15. The proposed policy can reduce the cost of emergency replenishment significantly from that of Alternative Policy 1. In addition, it is shown that the cost of emergency replenishment can be reduced from that of Alternative Policy 2 by introducing reduplicated replenishment. When the lead time of normal replenishment is long, the steady-state probabilities of each stage increase. As a result, the components that depend on emergency replenishment at the normal replenishment interval increase. The proposed policy can change the states of starting an emergency replenishment for each stage. However, the tracking information cost for the proposed policy is significantly higher than those of Alternative Policies 1 and 2. Therefore, the effectiveness of using tracking information decreases when the tracking information cost per unit increases.

Figures 17 and 18 show the steady-state probabilities at each state that cause the results of Figure 16. The states shown with solid, broken, and dotted lines show the states of starting normal, reduplicated normal, and emergency replenishments,
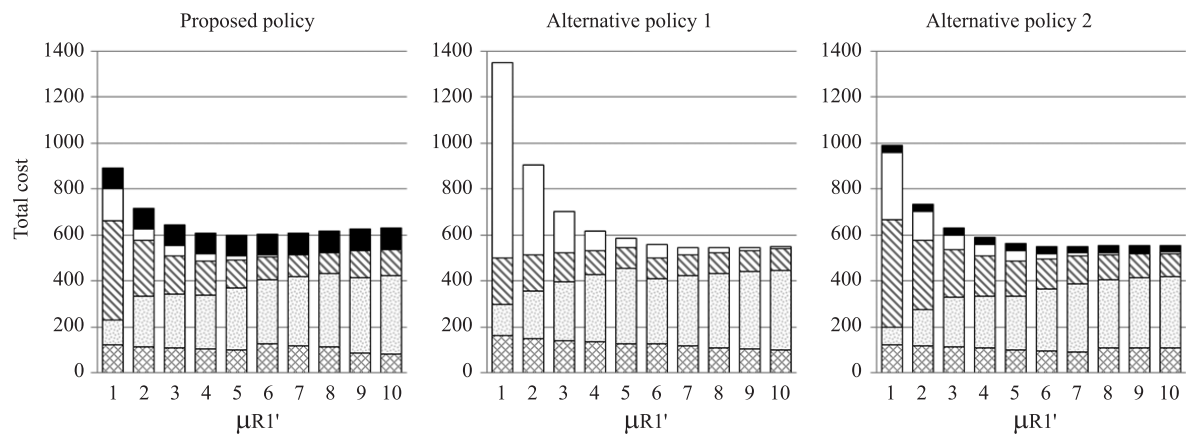

圂 Holding cost (warehouse) $\square$ Holding cost (retailer)

$\mathbb{N}$ Shortage cost $\square$ Emergency replenishment cost

Tracking irformation cost

Figure 16. Influence of the lead time of normal replenishment on each component of the total cost.
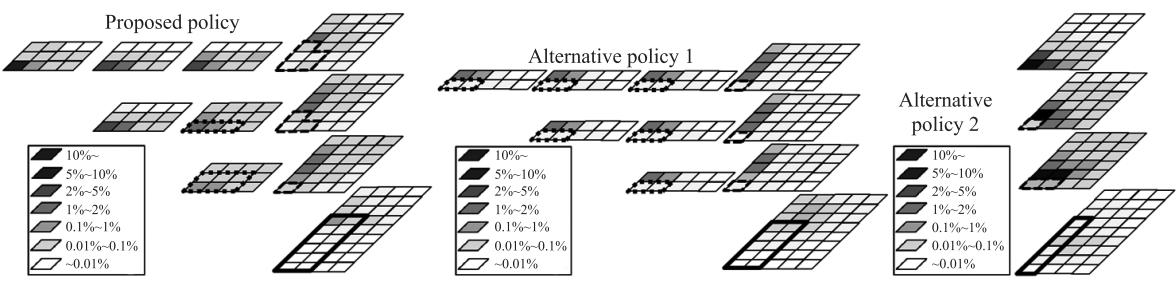

Figure 17. Steady state probabilities for $\mu_{\mathrm{R} 1}=1$ and $\mu_{\mathrm{r}}=100$. 

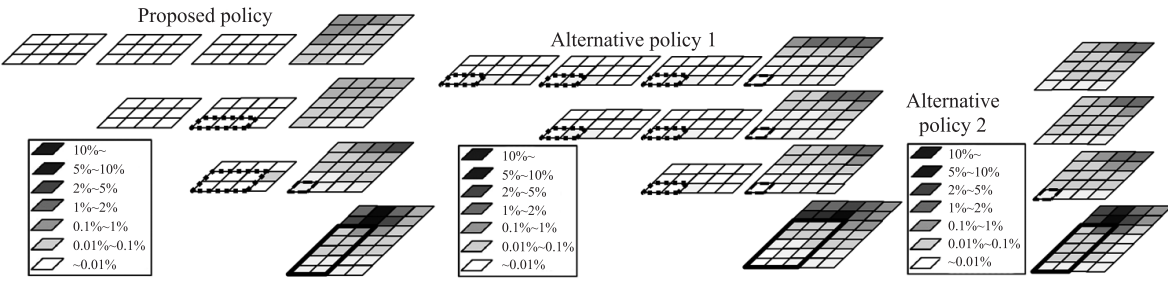

Figure 18. Steady state probabilities for $\mu_{\mathrm{R} 1}=10$ and $\mu_{\mathrm{r}}=100$.

respectively. The summation of the steady-state probabilities in the states of starting an emergency replenishment (shown with dotted line) for the proposed policy is about $0.1 \%$ when the lead time of normal replenishment is long, as shown Figure 17. In contrast, that for Alternative Policy 1 is about 1.5\%. Because Alternative Policy 1 does not use tracking information, it can be claimed that using tracking information leads to avoidance of unnecessary emergency replenishment by the proposed policy. As a result, the cost of emergency replenishment increases, leading to an excessive inventory holding cost for the retail store. This result proves the total cost breakdown shown in Figure 16. It is therefore proven that the effectiveness of tracking information is high for a long lead time of normal replenishment.

However, the summation of the steady-state probabilities in the states of starting an emergency replenishment (shown with dotted line) for Alternative Policy 2 is about $0.6 \%$ when the normal replenishment lead time is long. Alternative Policy 2 does not use reduplicated replenishment and fulfills all demands that occur during the lead time of a normal replenishment by emergency replenishment. As a result, the cost of emergency replenishment cannot be reduced as much, even by using tracking information. This explains why the effectiveness of reduplicated normal replenishment is high for a long lead time of normal replenishment.

In contrast, Figure 18 shows the steady-state probabilities for a short lead time of normal replenishment $\left(\mu_{\mathrm{R} 1}=10\right.$ and $\left.\mu_{\mathrm{r}}=100\right)$. For each policy, the summation of the steady-state probabilities when reduplicated normal replenishment is performed (shown with broken line) is less than 1\%. In Figure 17, the summations for the proposed policy and Alternative Policy 1 are about $60 \%$. This means that the effectiveness of reduplicated normal replenishment is low for a short lead time of normal replenishment. Concomitantly, the effectiveness of tracking information in determining the states of starting a reduplicated normal replenishment and an emergency replenishment is not as significant for a short lead time of normal replenishment.

\section{Conclusion}

In this paper, an inventory control policy for a dual-channel supply chain that uses tracking information is proposed. A Markov chain model that considers demand arrivals during long and uncertain replenishment lead times for dual-channel supply chains and an inventory control policy that uses tracking information are proposed. In the control policy, reduplicated replenishment and emergency replenishment are introduced, and the cost of using tracking information is considered. The proposed 
policy, which uses not only normal replenishment but also reduplicated replenishment and emergency replenishment, can fulfill demands that arrive during a long and uncertain lead time of replenishment. The performance of the proposed policy is evaluated and compared with two policies, one without tracking information and the other without reduplicated normal replenishment.

Results show that the total cost of the proposed policy is much less than those of the alternative policies, especially for the long lead time of normal replenishment. Moreover, the influences of the lead time of emergency replenishment on the total cost of each policy are not small for a long lead time of normal replenishment. Then, it can be claimed that the proposed policy is effective when the lead time of normal replenishment is long.

Also, results show that the total cost of the proposed policy is much less than those of the alternative policies, especially for the lower unit tracking information cost and the higher unit emergency replenishment cost. Moreover, the influences of unit emergency cost on the total cost of each policy are not small for a small unit tracking information cost. Then, it can be claimed that the proposed policy is effective when the tracking cost is low and the emergency replenishment cost is high.

Therefore, it is shown that the effectiveness of tracking information and reduplicated replenishment is high for a long and uncertain lead time of replenishment. In addition, if the tracking information cost is an imposed expense, the proposed policy becomes not effective under certain conditions.

In this paper, the number of stages $\mathrm{K}$ is considered an input parameter. If a decision-maker wants to determine the number of stages, he must develop the model with decision variable $\mathrm{K}$ and improve the effectiveness of tracking information. This can be suggested as an interesting research work.

\section{References}

Bendoly, E. (2004) Integrated inventory pooling for firms servicing both on-line and store demand. Computers \& Operations Research, Vol. 31, No. 9, pp. 1465-1480. http://dx.doi. org/10.1016/S0305-0548(03)00102-3

Cai, G.; Zhang, Z.G. and Zhang, M. (2009) Game theoretical perspectives on dualchannel supply chain competition with price discounts and pricing schemes. International Journal of Production Economics, Vol. 117, No. 1, pp. 80-96. http://dx.doi.org/10.1016/j.ijpe.2008.08.053

Cao, L. and Yushin, H. (2009) Channel coordination through a revenue sharing contract in a two-period newsboy problem. European Journal of Operational Research, Vol. 198, No. 3, pp. 822-829. http://dx.doi.org/10.1016/j.ejor.2008.10.019

Chen, F.; Federgruen, A. and Zheng, Y-S. (2001) Coordination mechanisms for a distribution system with one supplier and multiple retailers. Management Science, Vol. 47, No. 5 , pp. 693-708. http://dx.doi.org/10.1287/mnsc.47.5.693.10484

Chiang, W.K. (2010) Product availability in competitive and cooperative dual-channel distribution with stock-out based substitution. European Journal of Operational Research, Vol. 200, No. 1, pp. 111-126. http://dx.doi.org/10.1016/j.ejor.2008.12.021

Chiang, W. K. and Monahan G. E. (2005) Managing inventories in a two-echelon dual-channel supply chain. European Journal of Operational Research, Vol. 162, No. 2, pp. 325-341. http://dx.doi.org/10.1016/j.ejor.2003.08.062 
Dumrongsiri, A.; Fan, M.; Jain, A. and Moinzadeh, K. (2008) A Supply Chain Model with Direct and Retail Channels. European Journal of Operational Research, Vol. 187, No. 3, pp. 691-718. http://dx.doi.org/10.1016/j.ejor.2006.05.044

Hua, G.; Wang, S. and Cheng, T.C.E. (2010) Price and lead time decisions in dualchannel supply chains. European Journal of Operational Research, Vol. 205, No. 1, pp. 113-126. http://dx.doi.org/10.1016/j.ejor.2009.12.012

Huang, W. and Swaminathan, J.M. (2009) Introduction of a second channel: Implications for pricing and profits. European Journal of Operational Research, Vol. 194, No. 1, pp. 258-279. http://dx.doi.org/10.1016/j.ejor.2007.11.041

Kurata, H.; Yaob, D-Q. and Liu, J.J. (2007) Pricing policies under direct vs. indirect channel competition and national vs. store brand competition. European Journal of Operational Research, Vol. 180, No. 1, pp. 262-281. http://dx.doi.org/10.1016/j.ejor.2006.04.002

Liu, B.; Zhang, R. and Xiao, M. (2010) Joint decision on production and pricing for online dual channel supply chain system. Applied Mathematical Modelling, Vol. 34, No. 12, pp. 4208-4218. http://dx.doi.org/10.1016/j.apm.2010.04.018

Liu, M.; Srinivasan, M.M. and Vepkhvadze, N. (2009) What is the value of real-time shipment tracking information?. IIE Transactions, Vol. 41, No. 12, pp. 1019-1034. http://dx.doi. org/10.1080/07408170902906001

Mahara, S.; Bretthauerb, K.M. and Venkataramanan, M.A. (2009) The value of virtual pooling in dual sales channel supply chains. European Journal of Operational Research, Vol. 192, No. 2, pp. 561-575. http://dx.doi.org/10.1016/j.ejor.2007.09.034

Mohsen, S. and Kourosh, E. (2009) Sole versus dual sourcing under order dependent lead times and prices. Computers and Operations Research, Vol. 36, No. 12, pp. 3272-3280. http://dx.doi.org/10.1016/j.cor.2009.03.001

Tamer, B. (2005) Competitive Stocking and Coordination in a Multiplechannel Distribution System. IIE Transactions, Vol. 37, No. 5, pp. 407-427. http://dx.doi. org/10.1080/07408170590885594

Yao, Z. (2009) Analysis and Evaluation of an Assemble-to-Order System with Batch Ordering Policy and Compound Poisson Demand. European Journal of Operational Research, Vol. 198, No. 3, pp. 800-809. http://dx.doi.org/10.1016/j.ejor.2008.10.016

Zhou, Y.; Min, J. and Goyal, S.K. (2008) Supply-chain Coordination under An Inventory-level-dependent Demand Rate. International Journal of Production Economics, Vol. 113, No. 2, pp. 518-527. http://dx.doi.org/10.1016/j.ijpe.2007.10.024

\section{Biography}

Hidehiro Nagao was a master course student of Graduate School of Engineering, Hiroshima University and graduated in 2011. Now, he is working as an industrial engineer in an automobile parts manufacturing company.

Contact: h.nagao@hiroshima-u.ac.jp

Katsuhiko Takahashi is a professor of production systems engineering in Graduate School of Engineering, Hiroshima University, Japan. His research interest is production control systems and supply chain management.

Contact: takahasi@hiroshima-u.ac.jp 
Katsumi Morikawa is an associate professor of production systems engineering in Graduate School of Engineering, Hiroshima University, Japan. He has interest in production planning and scheduling.

Contact: mkatsumi@hiroshima-u.ac.jp

Daisuke Hirotani is an assistant professor of production systems engineering in Graduate School of Engineering, Hiroshima University, Japan. He has interest in production systems.

Contact: dhiro@hiroshima-u.ac.jp

\section{Article Info:}

Received: September, 2011

Accepted: December, 2011 